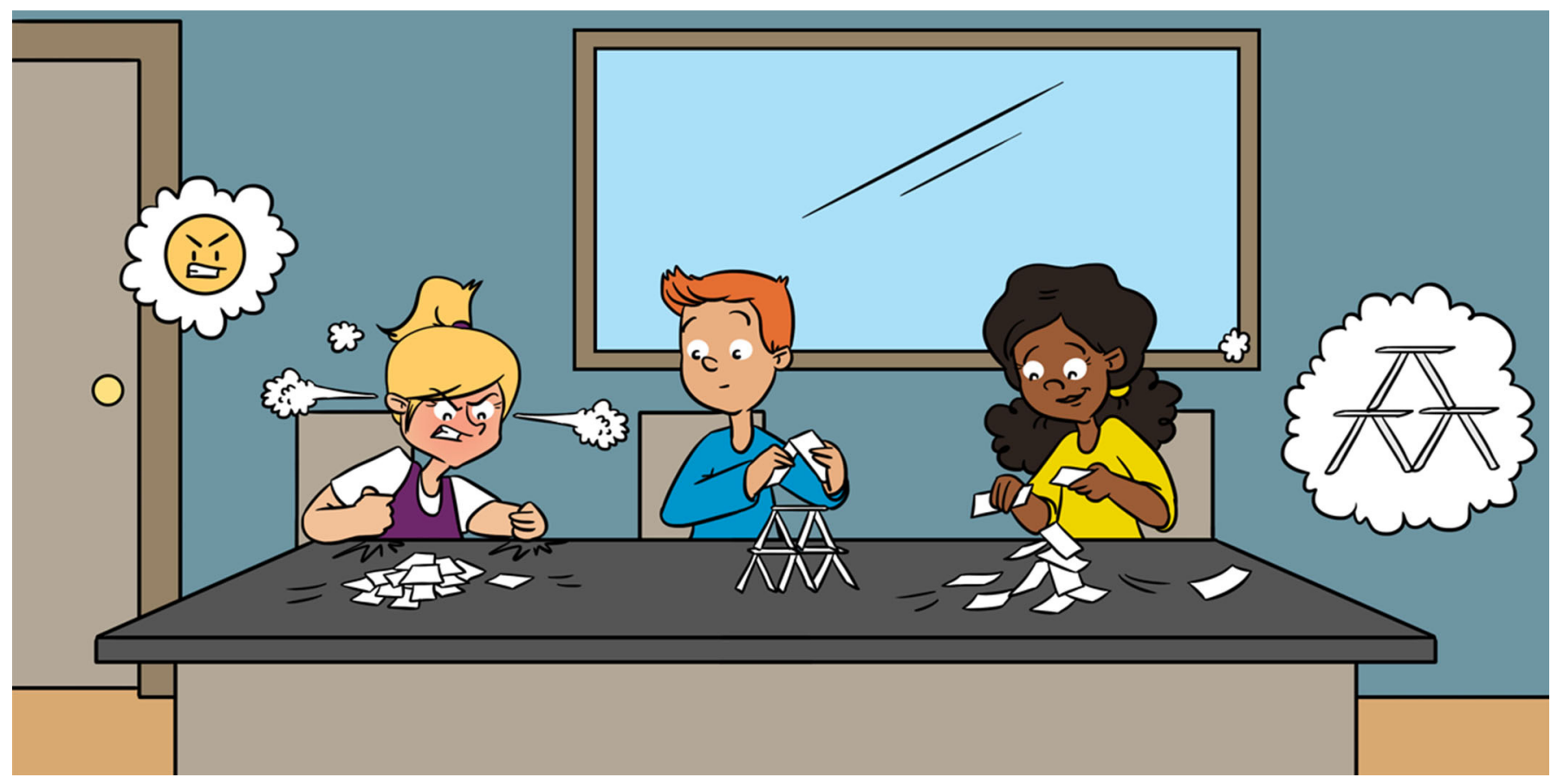

\title{
WHY ARE SOME CHILDREN MORE EASILY FRUSTRATED THAN OTHERS? IRRITABILITY AND THE BRAIN
}

\section{Elisabet Blok ${ }^{1}$ and Tonya White ${ }^{1,2^{*}}$}

${ }^{1}$ Department of Child and Adolescent Psychiatry/Psychology, Erasmus University Medical Centre-Sophia Children's Hospital, Rotterdam, Netherlands

${ }^{2}$ Department of Radiology and Nuclear Medicine, Erasmus University Medical Centre, Rotterdam, Netherlands

YOUNG REVIEWERS:

ORGANIZATION FOR

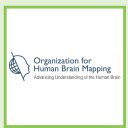
HUMAN

BRAIN MAPPING AGES: 8-15 REINA AGE: 9
Some children can handle big problems without getting upset, while other children quickly become frustrated or irritable. If we want to understand why some children become more frustrated or irritable than other children, we need to study the brain, because the brain controls behavior. To understand irritability in children, we need to learn about three things. First, we need to know how children recognize the emotions of other people, because if children are not able to understand the emotions of other children, they might get frustrated. Second, we need to learn about how it feels to get a reward, because children who expect a reward, but do not get one, can become frustrated. Finally, we can ask how we can teach children to cope better. Learning about how children's brains work can help us to understand why some children become frustrated or irritable more quickly than other children. 
MAGNETIC

RESONANCE

IMAGING (MRI)

Method researchers use to look at the structure and function of the brain. For example, functional MRI can be used to see what regions of the brain are active while a person performs different tasks.

\section{FRUSTRATION}

An emotional response that can be experienced when you were promised something but you do not get it.

\section{IRRITABILITY}

Negative emotions or feelings often felt in response to frustration.

\section{IS YOUR BRAIN UNIQUE?}

Everyone who has seen the Disney movie "Inside Out" knows about Riley. For those who have not seen the movie, Riley is a girl with a control center in her brain where all her emotions are located. The emotion with the name Joy tries to make Riley happy, and the emotion Fear protects Riley from danger. Riley's emotions control her behavior. While growing up, Riley moves from Minnesota to San Francisco, and on the first day at her new school everything goes wrong. Two emotions, Joy and Sadness, get lost in Riley's brain and must get back to the control center. In the meantime, we see how Riley's feelings and behavior change because she is now controlled by her remaining emotions: Fear, Anger, and Disgust!

Riley's brain is shown in a way that is simpler than how the brain really works, but the movie does a nice job showing how emotions can change behavior. Just like in Riley's brain, all our thoughts and emotions can influence each other. If we understand more about how our brain works, we can understand why everyone behaves in their own unique way!

\section{HOW DO WE STUDY THE BRAIN?}

In the movie Inside Out, we can look straight into Riley's brain and see the different emotions that she is experiencing. Of course, in real life we cannot look inside the brain! However, we do have a machine, called a magnetic resonance imaging (MRI) scanner. The MRI scanner can create a picture of not only how your brain looks, but also how it works. MRI scanners can show researchers which part of the brain is being used when a person is doing a certain activity or feeling a certain emotion. For example, when you are coloring, some parts of your brain are active, like the brain area that controls your hand. Feeling frustration or irritability also involves specific parts of the brain.

If you think about your friends, probably some of them can handle big problems without getting upset, while others quickly become frustrated or irritable. By studying the brain, we can learn why some children become more frustrated or irritable than other children. If we understand why some children are more irritable, we can better help them cope with this irritability so that ultimately, they can handle big problems without getting really upset.

\section{RECOGNIZING THE EMOTIONS OF OTHERS WITH YOUR "ALMOND"}

While talking with your friends, you see their emotions on their faces. If a friend is sad, you will see it on their face. So, you try to cheer your friend up and when your friend's face shows a smile, you know that 
Figure 1

Three brain regions involved in irritability. This image is drawn as if the person is facing left and you were looking at the brain from the side.

\section{AMYGDALA}

An almond-shaped structure in the brain. One of the jobs of the amygdala is processing of recognizing emotions.

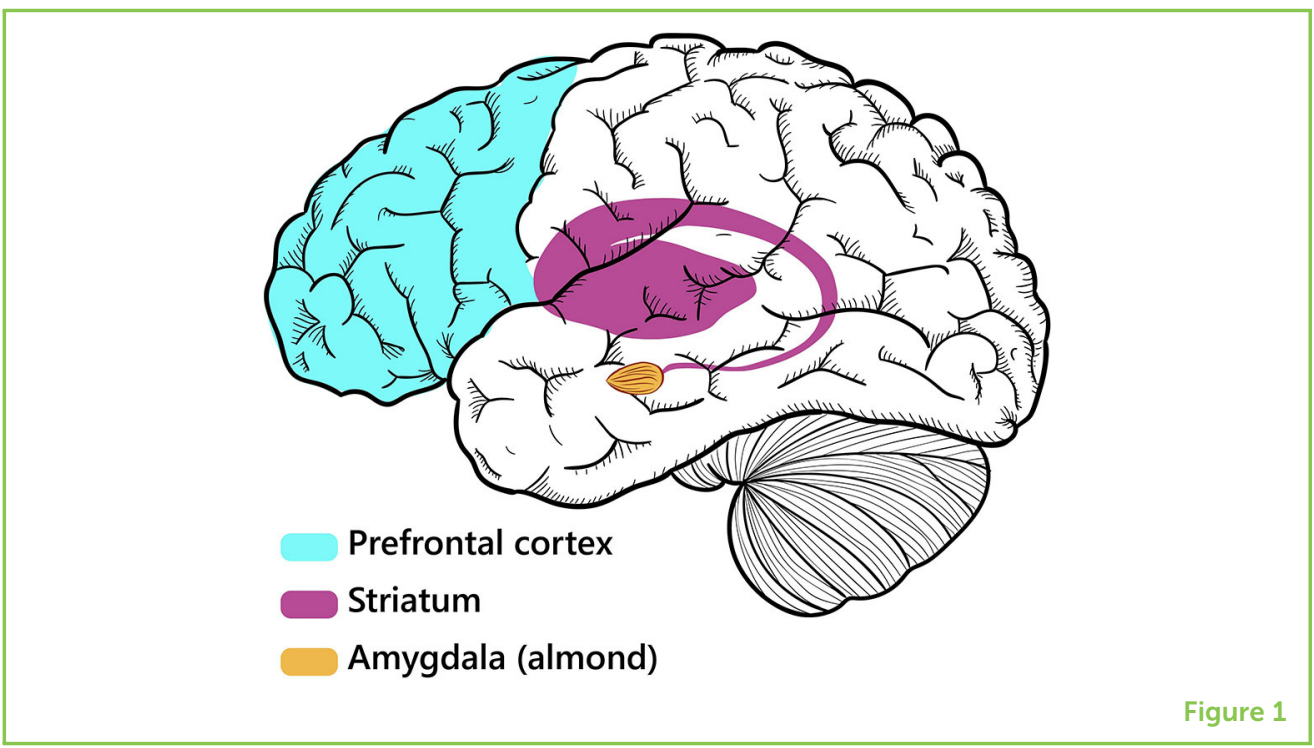

they are feeling better. Now imagine if it were hard for you to recognize that your friend is sad. It would then be a lot harder to know how to respond to your friend. So, you can see that recognizing the emotions of others is important for being a good friend.

What does all of that have to do with an almond? Well, there is a region in the brain that is shaped like an almond. The Greek name is for this region is amygdala (Figure 1). That almond, the amygdala, is important for many different tasks, one of which is being able to recognize the emotions of others. Researchers wondered if children who are irritable have more trouble recognizing the emotions of others. Maybe the activity of the amygdala is different in children with irritability than in children without irritability when they are trying to understand the emotions of others.

To study this possibility, 71 children participated in a study. While they were in an MRI scanner, they looked at photos of people and were asked to name the emotions of the people in the photos. The researchers found that the brain activity in the amygdala was different in children with irritability. Children who were more irritable were more likely to say that faces were angrier than they really were [1]. If you see someone looking angrily at you, it can be frustrating. So, children with irritability are more likely to think that someone is angry at them. This might explain why they are more frustrated than other children (Figure 2A).

\section{EXPECTING REWARDS: A JOB FOR THE STRIATUM}

Can you imagine a time where you were promised to get something for doing a chore? For example, imagine you were promised that, after cleaning your room, you could watch TV. But, after cleaning your 


\section{Figure 2}

Three ways that children can get irritable. Irritability can happen when children (A) see faces of others angrier than they really are, (B) expect a

reward, but do not get one, or (C) spend so much energy focusing on their frustration that they cannot focus on other things.

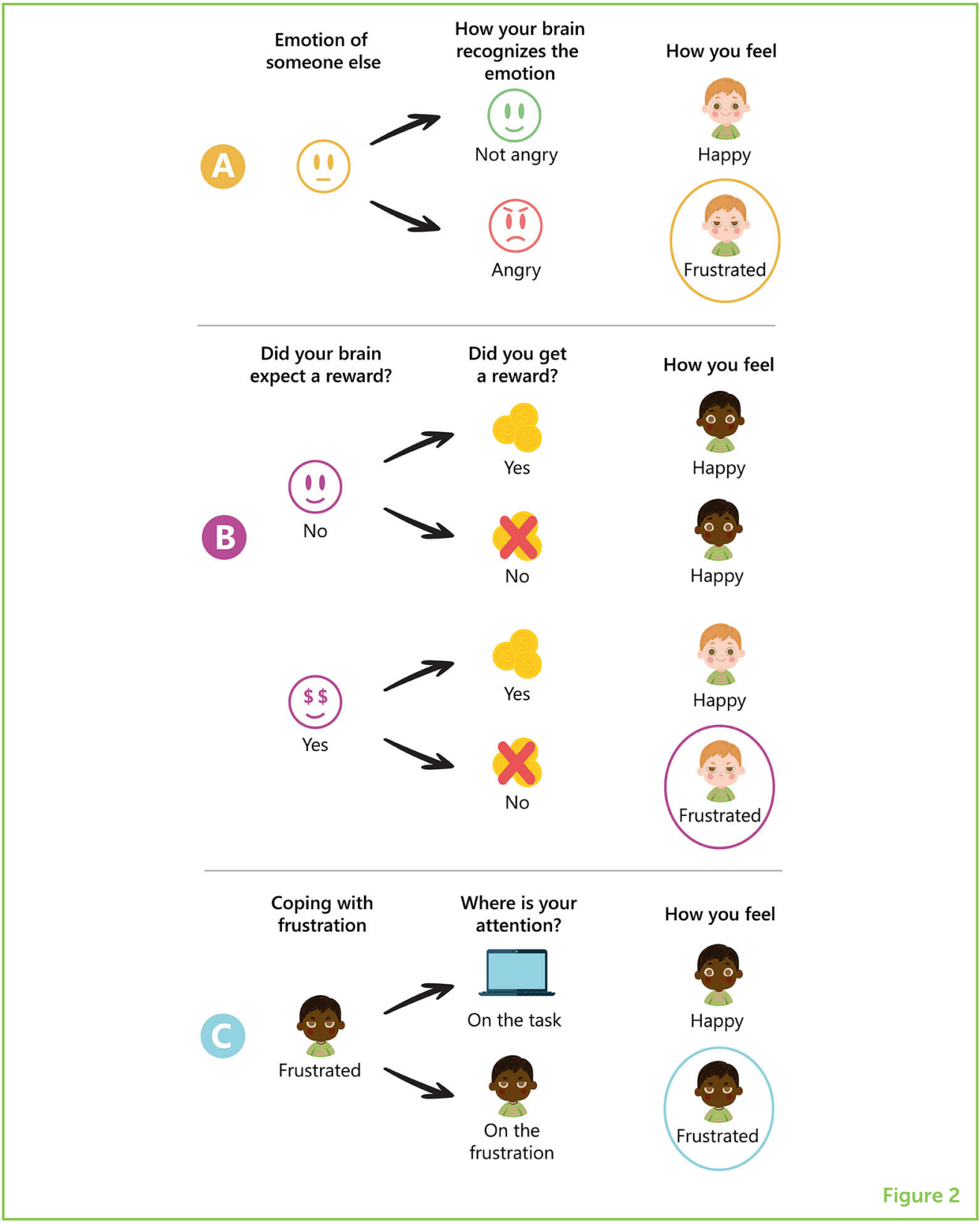

room, your mom suddenly says that you cannot watch TV! How would that make you feel? Pretty frustrated, of course! Now imagine you were asked to clean your room without the promise that you could watch TV afterwards. When you finish cleaning and your mom gives you a reward by letting you watch TV, you are happy. But, if after you clean your room you do not get a reward, you are still happy-you would not be frustrated because you did not expect to be rewarded. So, whether we expect a reward can influence whether we get frustrated or not. When children have problems knowing when they should get a reward and they think that they should be rewarded a lot, they will probably get frustrated more often (Figure 2B).

To study how the brain works when children think they should get a reward, children performed a task in the MRI that was designed 
Figure 3

Comparing amygdalae to almonds. Your brain has a left and a right side that are connected in the middle. Both sides of your brain have an amygdala, so you have a left and a right amygdala. The blue box shows the mean (or average) volume of the left amygdalae, the red box shows the right amygdalae, and the green box shows the volume for the almonds (experimental details are in Box 1). You can see that, in general, amygdalae are larger than almonds. However, the "whiskers" protruding from each box show the variation in the data, and you can see that the green and blue "whiskers" slightly overlap. This means there are some almonds that are the same size as an amygdala.

\section{STRIATUM}

A brain structure important for telling you whether you expect a reward or not.

\section{PREFRONTAL}

\section{CORTEX}

A large part of the brain that is located right behind the forehead. While all brain regions are important, in relation to the entire brain, the prefrontal cortex is much larger in humans compared to any other mammal. One of the tasks of the prefrontal cortex is controlling emotions.

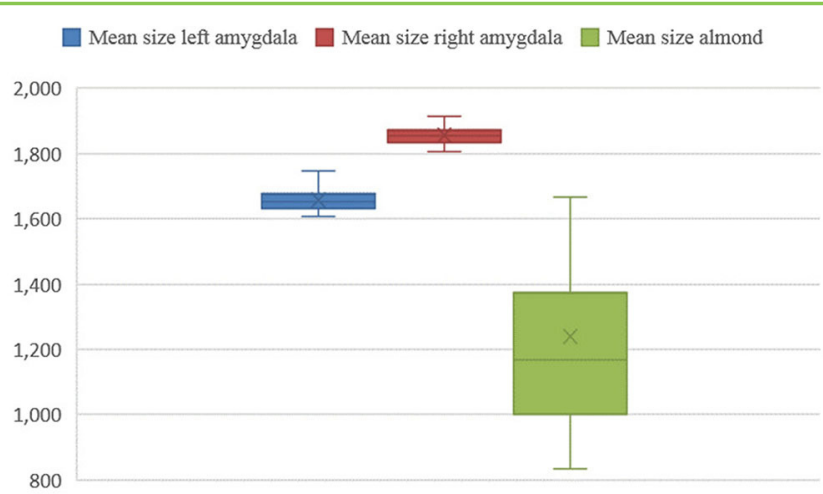

Figure 3

Box 1 | Is an almond the same size as a real amygdala?

After reading about the amygdala, you might wonder: is an almond the same size as a real amygdala? To answer this question, we compared the volume of almonds to the amygdala volume of children (age 9-11) that participated in our study [5]. For this experiment we used: (1) one cup of almonds, bought at the local supermarket, (2) one measuring cup, filled with $200 \mathrm{ml}$ of water, and (3) brain scans of 4,000 children. We randomly selected 30 amygdalae and 30 almonds and calculated their mean volumes. The amygdalae volumes were calculated with a computer program. To calculate the volume of the almonds, we filled the measuring cup with $200 \mathrm{ml}$ of water, placed our 30 almonds inside the measuring cup, and measured how much the water rose. We repeated the random selection 30 times, calculating 30 mean amygdala and 30 mean almond volumes. We plotted the measurements in Figure 3. We found that, in general, the amygdalae of the children are larger than almonds! But, if you look at the data closely, you can see that some amygdalae are the size of some almonds.

to make them feel some frustration. Researchers made the task frustrating by sometimes telling children they got the task wrong, even when they did it right! The researchers then looked at the children's brains when they were frustrated. The researchers located a brain region that was less active when the children were frustrated [2]. This brain region is called the striatum (Figure 1), and it tells you whether to expect a reward or not. This finding is interesting, because we think that the children with irritability were more upset than the non-irritable children when they were told that they were wrong when they were actually right. While everyone thought that they would get a reward because they got right answer, the irritable children got more frustrated when they did not get a reward.

\section{COPING WITH FRUSTRATION: TO THE FRONT!}

We showed that frustration can come from different brain activity in the amygdala and the striatum. Now we are going to look at the part of the brain that tries to control frustration. Children use different strategies to control their emotions. One option is to focus on something that is not frustrating. The part of your brain that is involved in focusing attention on something else is in the front of the brain, right behind the forehead. We call it the prefrontal cortex (Figure 1). 
Researchers invited 200 children to do a similar task as described above in the MRI scanner, in which the researchers tried to get the children a little frustrated [3]. What they noticed was very interesting. The prefrontal cortex was more active in the children who were more irritable. This may mean that the children with irritability were trying extremely hard to focus on the task rather than on the frustration that they felt. Remember, this task is frustrating for everyone. The children with irritability were trying even harder to cope with their frustration (Figure 2C). So, children who are more irritable may need to use more "brain power" to deal with their frustration than children who are not irritable. When the brain needs to work harder than usual, then other tasks become even more difficult or can make someone feel even more frustrated. Say, for example, that you feel frustrated because you had a bad day at school where nothing seemed to go right. You get home and your brain is working hard to control your frustration. But then your little brother has a new toy that makes lots of noise and your father asks you if want to practice words for your spelling test. Then your mother reminds you that your room is a mess and that you said you would clean it yesterday, and you shout at her. You normally would not shout at your mom, but because your brain is using lots of "brain power" to control the frustration, the brain does not want more things coming in. As you can see by this example, situations in daily life are often more challenging than tasks that researchers ask children to do in the MRI. However, the reserachers did find that with more challenging situations, more brain power is needed, and it becomes too hard to cope with the situation, and this could lead to more problems in school, with friends, and with family.

\section{WHAT IS NEXT?}

Now you know quite a bit about irritability and the brain. Your brain is just like Riley's, with a control center that is full of different types of emotions. You have learned how we can measure brain function using an MRI scanner and that there are three key brain regions that function differently in children with irritability. But there is so much more that we still need to learn about how the brain works in children who are irritable [4]. So, what are the next steps? Well, if we think back to Riley, her behavior changed dramatically when she was controlled by only some of her emotions. In real life, everyone has some level of irritability. Your brain might look a lot like those of other children. However, if you are easily frustrated, maybe your frontal regions must work just a bit harder than those of other children. What we want to know now is whether we all have to work to control our frustration, and whether, if we learn to have more control over our frustration, we can then see changes in the brain. By learning how the brain works in children who become easily frustrated, we can see if the brain becomes more normal after we teach these children better ways of coping. Perhaps some ways of learning to cope are better than others and we can test this in the MRI by seeing how much "brain power" children use when 
they are trying to cope. Understanding how the brain works in children who become easily irritable is the first step, the next step is to teach children better ways to cope and see if the brain uses less power to do certain tasks.

\section{REFERENCES}

1. Wiggins, J. L., Brotman, M. A., Adleman, N. E., Kim, P., Oakes, A. H., Reynolds, R. C., et al. 2016. Neural correlates of irritability in disruptive mood dysregulation and bipolar disorders. Am. J. Psychiatry 173:722-30. doi: 10.1176/appi.ajp. 2015.15060833

2. Deveney, C. M., Connolly, M. E., Haring, C. T., Bones, B. L., Reynolds, R. C., Kim, P., et al. 2013. Neural mechanisms of frustration in chronically irritable children. Am. J. Psychiatry 170:1186-94. doi: 10.1176/appi.ajp.2013.12070917

3. Tseng, W. L., Deveney, C. M., Stoddard, J., Kircanski, K., Frackman, A. E., Yi, J. Y., et al. 2019. Brain mechanisms of attention orienting following frustration: associations with irritability and age in youths. Am. J. Psychiatry 176:67-76. doi: 10.1176/appi.ajp.2018.18040491

4. Meyers, E., DeSerisy, M., and Roy, A. K. 2017. Disruptive mood dysregulation disorder (DMDD): an RDoC perspective. J. Affect. Disord. 216:117-22. doi: 10.1016/j.jad.2016.08.007

5. White, T., Muetzel, R. L., El Marroun, H., Blanken, L. M. E., Jansen, P., Bolhuis, K., et al. 2018. Paediatric population neuroimaging and the generation R study: the second wave. Eur. J. Epidemiol. 33:99-125. doi: 10.1007/s10654-017-0319-y

SUBMITTED: 03 May 2020; ACCEPTED: 12 November 2020;

PUBLISHED ONLINE: 10 December 2020.

EDITED BY: Julia W. Y. Kam, University of Calgary, Canada

CITATION: Blok E and White T (2020) Why Are Some Children More Easily Frustrated Than Others? Irritability and the Brain. Front. Young Minds 8:558673. doi: $10.3389 /$ frym.2020.558673

CONFLICT OF INTEREST: The authors declare that the research was conducted in the absence of any commercial or financial relationships that could be construed as a potential conflict of interest.

COPYRIGHT @ 2020 Blok and White. This is an open-access article distributed under the terms of the Creative Commons Attribution License (CC BY). The use, distribution or reproduction in other forums is permitted, provided the original author(s) and the copyright owner(s) are credited and that the original publication in this journal is cited, in accordance with accepted academic practice. No use, distribution or reproduction is permitted which does not comply with these terms. 

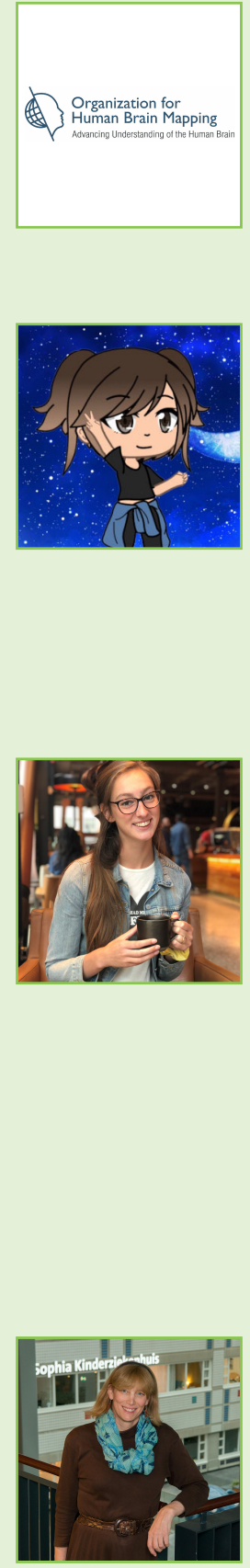

\section{YOUNG REVIEWERS}

\section{ORGANIZATION FOR HUMAN BRAIN MAPPING, AGES: 8-15}

As part of the Kids Live Review Event at OHBM 2020, Adrian, Louie, Pinaki, Reina, and Tian, grilled the scientists on their work in front of an audience. This group of elite reviewers provided pointed feedback that improved the quality of each of these papers, ranging from boredom, irritability, and social learning, to brain surgeries and Alzheimer's disease.

\section{REINA, AGE: 9}

My name is Reina and I am going into grade 5 next year. I like to draw on my iPad, and write stories. My brother and I collect Pokemon cards and we enjoy going on bike rides with my parents. I also like to dance ballet, jazz, and acro. My favorite colors are blue and violet. I love winter, fall, and summer, but I dislike spring because it rains a lot. When I grow up, I want to be an architect or an author.

\section{AUTHORS}

\section{ELISABET BLOK}

Hello, thanks for taking the time to look at our article. I am both a medical student and a Ph.D. student in the Department of Child and Adolescent Psychiatry/Psychology at the Erasmus University Medical Centre in Rotterdam. In the last 2 years, I have spent a lot of time scanning teenagers that participate in the Generation R Study. Now that we have scanned all teenagers, I get to spend most of my time studying how brain development is different for children with behavioral problems than for typically developing children. I am especially interested in children who become easily irritable and frustrated and hope that in the future I can help them better learn to cope. Besides work, I love playing music. I play the piano as well as organ (although I do not have an organ at home). Further, I like to spend time with friends and family.

\section{TONYA WHITE}

Hello, thanks for taking the time to look at our article. I am an associate professor of child and adolescent psychiatry and radiology at the Erasmus University Medical Centre in Rotterdam, the Netherlands. In my research, I use magnetic resonance imaging (MRI) machines to study how the brain develops throughout childhood and adolescence. My team has scanned over 8,000 children and teenagers at different ages. We study not only how the brain typically develops, but also how the brain looks and functions in children with emotional and behavioral problems. In my free time, I enjoy all winter sports, especially cross-country skiing. In the summer I like to bike and rollerski. And year-round I like to read and spend time with family. *t.white@erasmusmc.nl 